\title{
Microwave Fast Sintering of Submicrometer Alumina
}

\author{
Romualdo Rodrigues Menezes ${ }^{\mathrm{a}}$, Pollyane Marcia Souto ${ }^{\mathrm{b}}$, Ruth Herta Goldschmidt Aliaga Kiminami $^{\mathrm{b}}$ \\ ${ }^{a}$ Department of Materials Engineering, Federal University of Paraíba - UFPB, \\ CEP 58059-900, João Pessoa, PB, Brazil \\ ${ }^{\mathrm{b}}$ Ceramic Materials Synthesis and Processing Laboratory, Department of Materials Engineering, \\ Federal University of São Carlos - UFSCar, CEP 13565-905, São Carlos, SP, Brazil
}

Received: January 26, 2010; Revised: June 19, 2010

\begin{abstract}
Commercially available alumina powder with high-purity submicrometer particle size and narrow particle size distribution was fully densified by a microwave hybrid fast firing technique. The alumina compacts were surrounded by susceptor material, which helped the heating of the samples, and sintered in a microwave oven at a frequency of $2.45 \mathrm{GHz}$ and a power level of $1.8 \mathrm{~kW}$. The sintered samples reached densities of $99 \%$ in sintering cycles of 30 to 40 minutes, a much shorter time than conventional sintering processes. The sintered samples showed uniform microstructures with powder particle size/average grain size rations higher than 1:2.
\end{abstract}

Keywords: microwave processing, alumina, sintering

\section{Introduction}

The advantage of very fine-grained microstructures with submicrometer grain sizes to obtain components with improved hardness, wear resistance, strength, or optical performance is well known ${ }^{1,2}$. Several fabrication routes are available for the production of ceramics with high density and controlled grain size. These include colloidal processing of powders with a controlled (narrow) size distribution, various wet shaping methods, pressure sintering, spark-plasma sintering and related techniques and use of additives that are incorporated into solid solution or form a discrete second phase, e.g., liquid-phase sintering ${ }^{1,3-11}$. However, these fabrication routes can be uneconomical for many applications or can be difficult to apply successfully (e.g., choice of additives). Remarkable progress in both processing and properties has been achieved in recent years, but simple and economical routes are worthy of investigation? ${ }^{7}$.

Great achievements to date have involved use of pressure; for example, via hot pressing, hot isostatic pressing, sintering forging and the "spark plasma sintering" routes. However, these routes involve disadvantages, not the least of which is their coast, as well as a very limited shape capability ${ }^{12}$. The use of solutes to reduce grain boundary mobility or second-phase particles to pin the grain boundaries has been successful, but can only be pursued in a few systems because the addition of different phases can degrade the final properties of the product to levels unacceptable for many applications.

Control of the heating schedule to manipulate microstructure during sintering is an approach that has long been known to have the advantages of simplicity and economy. Numerous efforts have been made to investigate its effectiveness ${ }^{7}$. One of these is the rate-controlled sintering, in which attempts are made to keep the rate of densification approximately constant by controlling the temperature ${ }^{13}$ and a related two-peak firing ${ }^{14}$. Another method is the two-step sintering ${ }^{15-17}$, which exploits the competition between the driving forces of grain boundarycontrolled densification and grain boundary-controlled grain growth to achieve densification without grain growth during the final stage of sintering ${ }^{16}$ and the two-step sintering with an initial precorsening step prior to densification ${ }^{7,18,19}$. A third approach is non-isothermal rapidrate sintering. Non-isothermal rapid-rate sintering allows for a quick passage through temperature range where surface diffusion-controlled coalescence prevails over other sintering mechanisms ${ }^{16}$.
In fast firing, the objective is to enhance the ratio of densification rate to coarsening rate by a rapid approach to the sintering temperature. Because coarsening mechanisms (e.g., surface diffusion and vapor transport) commonly dominate over densification mechanisms (e.g., lattice and grain-boundary diffusion) at lower temperatures, it has been suggested that rapid heating to higher temperatures can be beneficial to achieve high density coupled with fine grain size ${ }^{20-24}$. In this case, the shorter time spent at lower temperatures serves to reduce the extent of coarsening while the driving force for densification is not decreased significantly ${ }^{19}$. However, there are some difficulties associated with conventional fast firing, such as non-uniform microstructures, low density and specimen cracking, which are related to differential sintering.

Use of microwaves allows transfer of energy directly into the materials, where it is converted to heat through absorption mechanisms such as ionic conduction, dipole relaxation, and photon-phonon interaction. Thus, microwave-sintering techniques allow a volumetric heating, which in turn allows application of high heat-up rates, markedly shortening the processing time ${ }^{25}$ and overcoming difficulties of conventional fast firing technique.

Application of microwaves for heating, sintering/densification, and annealing of ceramic powders and compacts is becoming a well-researched area that has been gaining industrial acceptance. Its advantages include the ability to deposit energy volumetrically in the sample and the possibility of rapid heating and cooling profiles ${ }^{26}$. This makes the use of microwave technology very attractive because of obvious economic benefits such as energy conservation, reduced cycle time, reduced operating space, and improved environment ${ }^{25}$. Most research on ceramic processing by microwaves to date is based on conventional low-frequency $(2.45 \mathrm{GHz})$ microwave applicators ${ }^{27}$. However, such applicators do not couple microwave power efficiently to low-loss ceramics, such as alumina, and large thermal gradients can often develop in the sample. Moreover, at high heating rates, these gradients may cause non-uniform properties and cracking ${ }^{26,28}$, which are obstacles to attain high heating rates with uniform volumetric heating of the ceramic body. 
Thermal insulation arrangements that reduce heat loss from the material's surface are commonly used to address the problem of thermal gradients in the body, as also does hybrid heating, whereby microwaves are supplemented with conventional heating. By combining infrared heating and microwave heating, the thermal gradients can be substantially reduced to obtain a uniformly heated sample ${ }^{29}$. The hybrid heating system will heat sample more readily at low temperatures, and at high temperatures will flatten out temperature profile inside the ceramic body ${ }^{30,31}$.

Production of dense ceramic parts with submicrometer grains and flawless microstructure is still one of the most challenging objectives in modern ceramic technologies ${ }^{10}$. Grain growth control during final steps of densification is an extremely important processing concern, due to the impact of grain size on the materials' properties. The need for retaining small grain sizes in ceramic compact requires development of processing routes that drastically suppress grain growth during densification ${ }^{8,32-35}$. Thus, the aim of this work is microwave hybrid fast sintering of submicrometer powders to obtain fully dense polycrystalline alumina with submicrometer grains.

\section{Experimental Procedure}

A commercial, high purity $\mathrm{Al}_{2} \mathrm{O}_{3}$ powder (AKP-53, purity $99.995 \%$, Sumitomo Chemical America, Inc., New York) was used in the experiments. According to the manufacturer's specifications, the as-received powder has an average particle size of $0.2 \mu \mathrm{m}$ and a surface area of $10.4 \mathrm{~m}^{2} \cdot \mathrm{g}^{-1}$. As described in detail elsewhere ${ }^{36,37}$, the powder was processed to remove hard agglomerates prior to compaction. Briefly the powder was dispersed in ethanol ( $\approx 25$ vol. (\%) solids) and ball milled for 22 hours in a polyethylene jar using zirconia milling media. $\left(\mathrm{MgCl}_{2}\right) \cdot 9 \mathrm{H}_{2} \mathrm{O}$, previously dissolved in ethanol, were added to the alumina dispersion in the amount required to obtain a $\mathrm{MgO}$-dopant concentration of $100 \mathrm{ppm}$. The milled dispersion was dried at room temperature under compressed air and continuous agitation. The dried material was passed through a 80-mesh sieve. The average particle size of the resulting powder measured by centrifugal sedimentation technique (Horiba Instruments, Model CAPA-720) was $0.21 \pm 0.08 \mu \mathrm{m}$.

Powder compacts for sintering were formed by uniaxial pressing under a pressure of $25 \mathrm{MPa}$, followed by cold isostatic pressure under a pressure of $200 \mathrm{MPa}$. Powder compacts of 2.0, 4.5 and $14.0 \mathrm{~g}$ were prepared. The 2.0 and $4.5 \mathrm{~g}$ samples had a diameter of approximately $20 \mathrm{~mm}$ and thicknesses of 2 and $4.5 \mathrm{~mm}$, respectively, while the $14.0 \mathrm{~g}$ sample had diameter of about $38 \mathrm{~mm}$ and was $4 \mathrm{~mm}$ thick. The compact had a relative green density of $\approx 60 \%$ of the theoretical density (3.986 g.cm ${ }^{-3}$ ). They were heated in a conventional furnace to $600^{\circ} \mathrm{C}$ at $5^{\circ} \mathrm{C} / \mathrm{min}$ for 2 hours of dwell time for binder removal. After binder removal, the samples were microwave hybrid sintered in a microwave furnace (multimode cavity) at $2.45 \mathrm{GHz}$ (Cober Electronics, MS6K) using homemade susceptor materials ${ }^{38}$ as auxiliary heating elements. Details of the sintering assembly are given elsewhere ${ }^{39}$. Samples were microwave-sintered using an input power of $1.8 \mathrm{~kW}$ and sintering times ranging from 25 to 40 minutes. The $2.0 \mathrm{~g}$ samples were also sintered in a conventional furnace (in air) (Lindberg Blue) at 1400, 1450 and $1500^{\circ} \mathrm{C}$ with a heating rate of $5^{\circ} \mathrm{C} / \mathrm{min}$ and a soaking time of 2 hours. The $2.0 \mathrm{~g}$ samples were also conventionally sintered at $1500{ }^{\circ} \mathrm{C}$ with soaking times of 4 and 6 hours.

The final densities of the compacts were measured by the Archimedes method ${ }^{40}$ using five samples for each determination. The microstructures of the microwave-sintered samples were observed by scanning electron microscopy (SEM) (Phillips, XL30 FEG) of fracture surfaces. The microstructures of the conventionally sintered samples were observed using polished and thermally etched surfaces. Specific regions of the microwave-sintered samples were observed and their grain size was measured by the linear-intercept technique using at least 600 grains for each region (a near-surface and an interior region, and the center of the samples). Details of the observed regions are re given elsewhere ${ }^{41}$. The average grain size of the samples was measured using five samples.

Microwave temperature measurements using a thermocouple in a hybrid heating arrangement have shown good agreement with measurements using optical-fiber thermometry and pyrometry for alumina and zirconia ${ }^{42}$. However estimates based on simulations conducted using a two-dimensional microwave-sintering code ${ }^{28,43}$ indicated temperature differences $>20^{\circ} \mathrm{C}$, with an upper limit of $30^{\circ} \mathrm{C}$. Another study ${ }^{44}$ showed that when microwaves are present during heating, the thermocouple can read $>150^{\circ} \mathrm{C}$ higher than the pyrometer, which is mainly due to a field enhancement effect. The predicted field pattern, instead of being uniform, is distorted and changes abruptly near the thermocouple tip. Such local variations in the electric-field (E) intensity cause even larger variations in the locally absorbed power density, which is proportional to $E^{2}$. Power deposition increases sharply near the thermocouple tip, causing increased localized heating results and possibly leading to thermal runaway and enhanced thermal gradients ${ }^{35}$. This indicated that the presence of the thermocouple within or near the sample had a strong effect on evolution of the temperature in the sample during microwave processing. Thus, based on the sintering arrangement used and aiming to avoid intensifying the electric field around the samples, the temperature of the compacts during the microwave hybrid sintering process was not measured.

The temperature inside the sintering arrangement was measured without the presence of the alumina compacts, using a fixed power of $1.8 \mathrm{~kW}$ and a platinum-sheathed type-B thermocouple, which was grounded to the oven cavity. Measurement of the sintering arrangement temperature without the samples aims minimize thermocouple tip effects, and thus, have a confidence value of the temperature reached by the susceptor material. The temperature was measured for fifteen minutes (due to the maximum temperature limitations of the thermocouple), and based on a mathematical model the sintering arrangement temperature was extrapolated to the compacts' sintering times ( 25 to 40 minutes). The purpose of this procedure was to estimate the temperature attained at the surface of the alumina compacts during the microwave hybrid sintering process due to the susceptor heating.

The temperature of the sintering arrangement was also estimated using other extrapolating methodology ${ }^{45}$. The system (susceptor and samples) was heated for thirty minutes at $1.8 \mathrm{~kW}$, a thermocouple was inserted through the isolation assembly after ( 8 minutes) turning off the power, touching the susceptor surface, and the temperature of susceptor was recorded. To minimize the effects of inserting the cold thermocouple, a very fine thermocouple type K covered by a fine insulating alumina tube was employed. To estimate the temperature attained by the susceptor, two assumptions were employed ${ }^{45}$. The first was that temperature decreased according to a definite cooling rate law from the instant that the microwave power was turned off, and the second was that the insertion of the thermocouple did not seriously affect the steady cooling curve. A mathematical model fitted the cooling curve and the maximum temperature attained by the susceptor was estimated by extrapolating the calculated curve to "time" zero.

\section{Results and Discussion}

Figure 1 presents the results for the relative densities versus sintering time of the microwave hybrid fast sintered alumina compacts and conventional sintered samples. The microwave-sintered samples weighing $2.0 \mathrm{~g}$ reached almost full density after 30 minutes of heating, while the $4.5 \mathrm{~g}$ samples reached its highest density after heating for 35 minutes. The sample weighing $14.0 \mathrm{~g}$ presented high density after 
heating for 40 minutes. It was observed that the density of the $2.0 \mathrm{~g}$ and $4.5 \mathrm{~g}$ samples did not increase further with sintering time after they reached their highest density. Comparing the density values with the results obtained in the conventional sintering it can be observed that the $2.0 \mathrm{~g}$ sample after only 30 minutes of heating reached the highest density value of the conventionally sintered samples. Based on previous conventional sintering studies ${ }^{36,37}$, which used the same procedure for powder de-agglomeration and compact forming, and a two-step technique with an initial coarsening step at $1050^{\circ} \mathrm{C}$ and

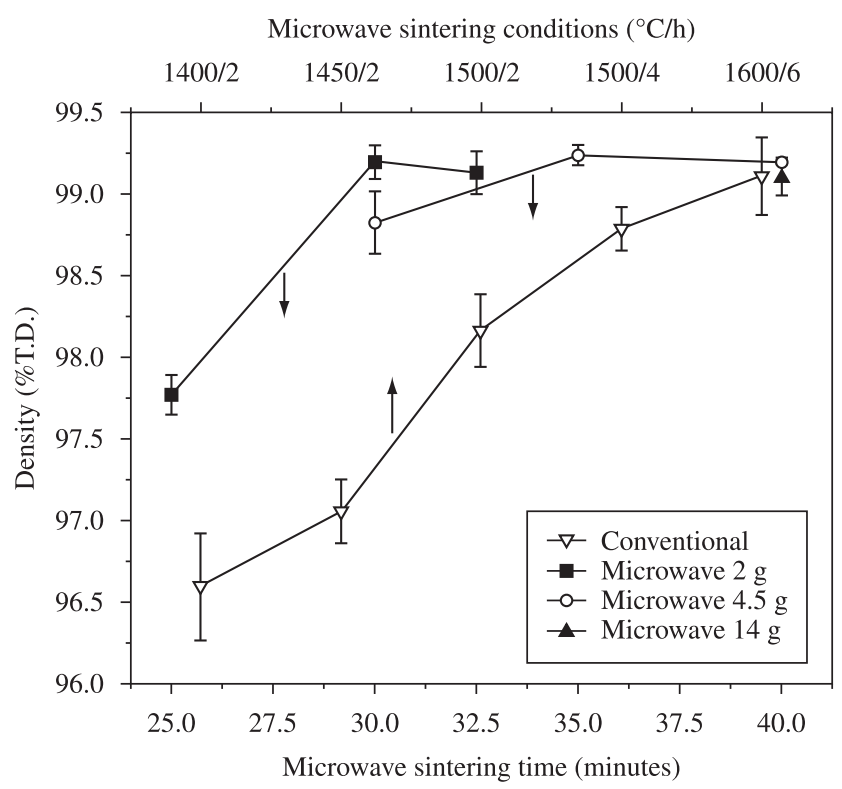

Figure 1. Relative density of microwave hybrid fast sintered and conventionally sintered alumina compacts. sintering at $1350^{\circ} \mathrm{C}$, which attained a relative density of $98.2 \%$, it was found that the fast firing method used here presented better results than the conventional sintering route, with densification results improved by more than $1 \%$ and sintering time reduced by more than $85 \%$.

The SEM micrographs of the fracture surfaces of the microwavesintered 2.0 and $14.0 \mathrm{~g}$ samples and the conventionally sintered sample are shown on Figures 2 and 3, respectively. The grain size distributions of the microwave sintered $14.0 \mathrm{~g}$ sample are presented at Figure 4. The final density and average grain size of the sintered samples are summarized in Table 1. It can be observed a very low grain growth, with powder particle size/average grain size rations higher than 1:2. This is higher than the values obtained in the conventional sintering study $^{36,37}(1: 3.5-4)$, in which the highest density attained was $98.2 \%$.

The microstructural homogeneity between the bulk and the near-surface regions of the compacts (in every samples) indicate that the microwave hybrid fast firing procedure used here produces a uniform volumetric heating of the samples, which is not always the case in the conventional fast firing and microwave fast sintering of low loss ceramics at $2.45 \mathrm{GHz}$. This microstructural homogeneity shows that the temperatures in the Center and in the Near-Surface regions of the samples were similar, and that the estimation of the maximum temperature reached on the samples surface will provide a good indication of the maximum samples' temperature reached during the sintering process.

Literature reports ${ }^{2}$ powder particle size to average grain size rations ranging from 1:3 to 1:5 for alumina compacts with densities of about $99 \%$ and an initial powder size of around $0.2 \mu \mathrm{m}$. These values result from pressureless sintering processes. The reported rations $^{2}$ for hot isostatic pressing (HIP) compacts (densities $\approx 100 \%$ ) ranged from 1:2 to 1:2.5. Compared with the literature ${ }^{2}$, the powder particle size to grain size ration obtained in this work is a very high value and indicated that the sintering procedure used here has a great potential to the processing of submicrometer alumina.

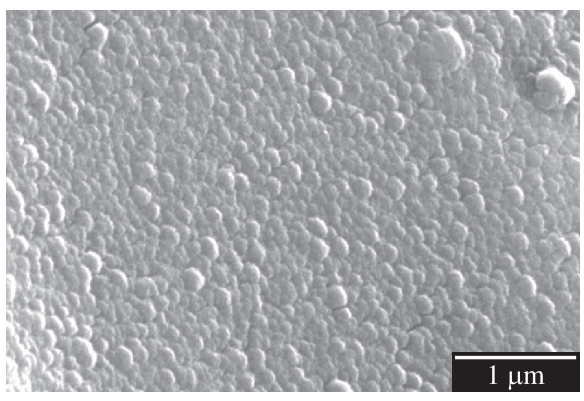

(a)

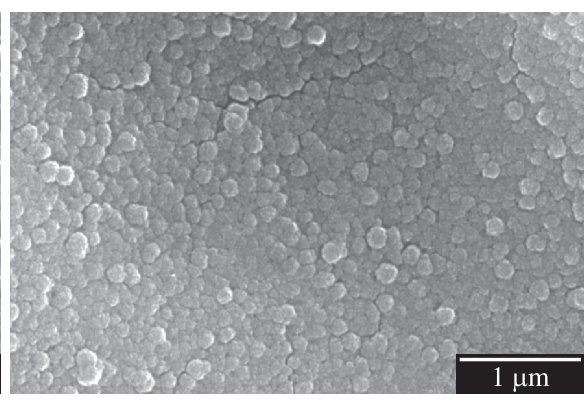

(b)

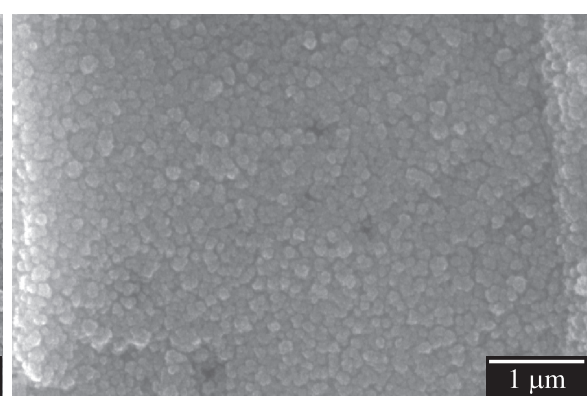

(c)

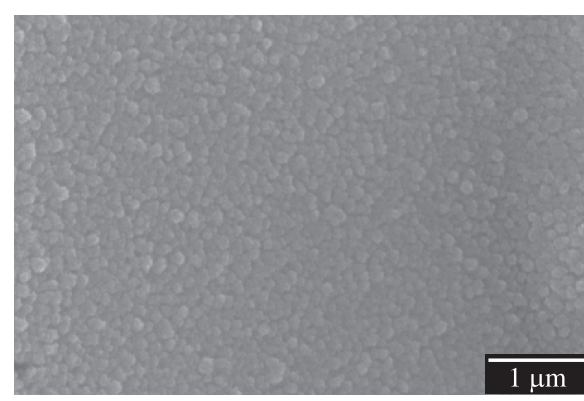

(d)

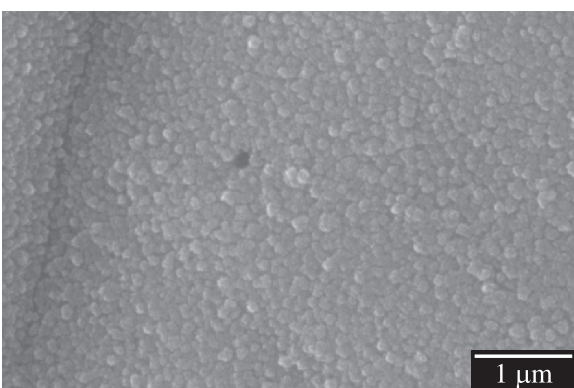

(e)

Figure 2. SEM micrographs of the fracture surfaces of the microwave hybrid fast sintered $2 \mathrm{~g}$ sample sintered for 30 minutes: a) near-surface region; b) interior region and of the microwave hybrid fast sintered $14 \mathrm{~g}$ sample sintered for 40 minutes; c) near-surface region; d) interior region; and e) center region. 


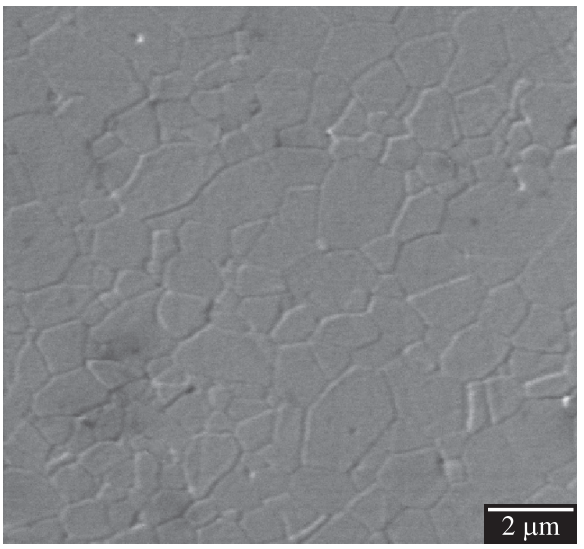

(a)

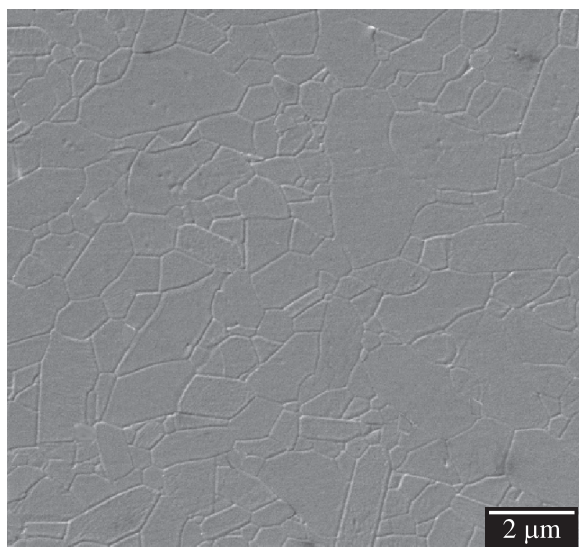

(b)

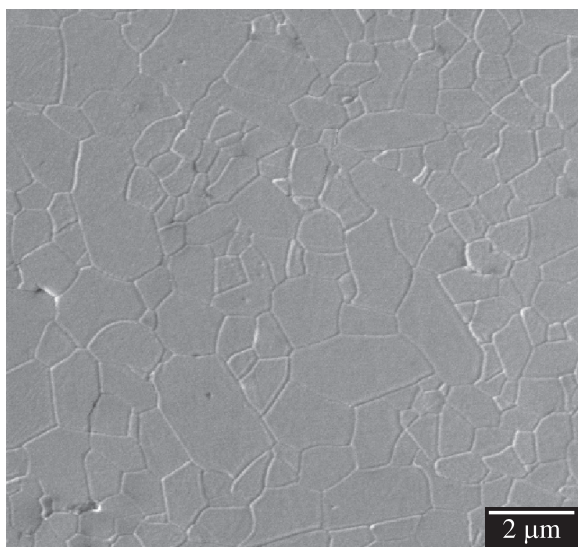

(c)

Figure 3. SEM micrographs of the conventionally sintered samples: a) at $1450{ }^{\circ} \mathrm{C}$ for 2 hours; b) at $1500{ }^{\circ} \mathrm{C}$ for 2 hours; and c) at $1500{ }^{\circ} \mathrm{C}$ for 6 hours.

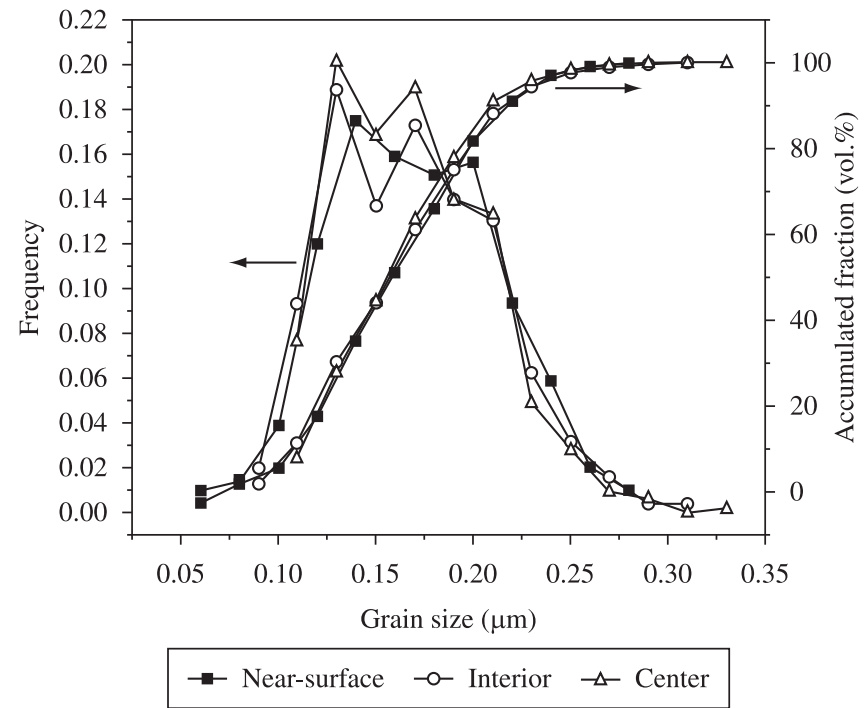

Figure 4. Grain size distribution of the microwave hybrid fast sintered $14.0 \mathrm{~g}$ sample.

There is a significant and gradual grain growth in the conventionally sintered samples with relative density (Table 1), and a noticeable difference in the grain growth trajectories for the microwave-sintered and conventionally sintered samples. The average grain size of $\approx 99 \%$ dense microwave-sintered sample is $\approx 20$ times lower than the average grain size of the conventionally sintered samples.

Figure 5a shows the temperature of the sintering arrangement measured when it was exposed to microwaves $(1.8 \mathrm{~kW})$. Note that the susceptor material reached almost $1600{ }^{\circ} \mathrm{C}$ in just 15 minutes, and that heating rates of up to $240{ }^{\circ} \mathrm{C} / \mathrm{min}$ were achieved at around $600^{\circ} \mathrm{C}$ (the heating rates were calculated through the differentiation of the measured heating curve). The heating rate decreased with rising temperature, which is attributable to the increase in thermal losses with temperature ${ }^{38}$, but reached values exceeding $100^{\circ} \mathrm{C} / \mathrm{min}$ at around $1150{ }^{\circ} \mathrm{C}$. A curve was fitted to the data presented in Figure 5a, using the equation $\mathrm{T}=\mathrm{a} \exp (\mathrm{b} /(\mathrm{c}+\mathrm{t}))$, where $\mathrm{a}=2020.87, \mathrm{~b}=-191.17$ and $c=-75.47$, obtaining a high degree of correlation between the function and the data $\left(\mathrm{R}^{2}=0.9993\right)$.
According to the calculated curve $(T=a \exp (b /(c+t)))$, Figure $5 \mathrm{a}$, the temperature was extrapolated to estimate the temperature of the sintering arrangement after 30 minutes of heating. Although the physical meaning of the equation obtained has not yet been clarified, the estimated temperatures attained after exposition to microwave at $1.8 \mathrm{~kW}$ for 30 and 40 minutes were to be 1800 and $1860{ }^{\circ} \mathrm{C}$, respectively. In this method of estimating temperature it was assumed that the susceptor material did not present uncontrolled thermal runaway after 15 minutes of heating. In previous studies ${ }^{38}$, which used a pyrometer to monitor the temperature of the susceptor material, but used a different heating arrangement, the uncontrolled thermal runaway of the susceptor was visually noticeable after the heating cycle. Based on this observation and on the visual aspect of the susceptors after the sintering cycles, it is assumed that the susceptors in this study did not undergo uncontrolled thermal runaway when heated for 40 minutes at $1.8 \mathrm{~kW}$.

Figure $5 \mathrm{~b}$ shows the cooling curve of the sintering arrangement after heating for 30 minutes at $1.8 \mathrm{~kW}$. A model fitted the data presented in Figure $5 b$ using the equation $T=a \exp (b / c+t)$, where $\mathrm{a}=64.83, \mathrm{~b}=10035.12$ and $\mathrm{c}=3016.69$, obtaining a high degree of correlation between the function and the data. According to the calculated curve $(\mathrm{T}=\mathrm{a} \exp (\mathrm{b} /(\mathrm{c}+\mathrm{t})))$, the temperature was extrapolated to time "zero" to estimate the maximum temperature of the sintering arrangement after 30 minutes of heating. Although the physical meaning of the equation obtained has not yet been clarified, the temperature estimated was $1805^{\circ} \mathrm{C}$, which is congruous with the temperature estimated by the first extrapolating method.

Based on the observed microstructure's homogeneity (Figures 4 and 6), it is supposed that the interior of the alumina compacts reached similar temperatures to that attained on their surfaces, which were estimated at around $1800^{\circ} \mathrm{C}$. This high sintering temperature is congruous to the fast firing technique approach ${ }^{19,46}$, which uses higher sintering temperatures than the conventional slow-heating procedures.

Many studies have reported unexpected effects resulting from the use of microwave radiation as an alternative energy source during the processing of materials. These results have included apparent evidence of accelerated kinetics for a range of processes in ceramic, polymeric, and organic systems, and enhanced sintering of ceramic powder compacts, including lower sintering temperatures. These unexpected effects are called the "microwave effect" general summary, the kinetics of synthesis and sintering reactions are reportedly ${ }^{48,49}$ augmented by 2 or 3 orders of magnitude or even more when conventional heating is substituted for microwave radiation. In sintering processes, the microwave effect is quantified by the 
Table 1. Relative density and average grain size of microwave and conventionally sintered samples.

\begin{tabular}{|c|c|c|c|c|}
\hline \multirow[t]{2}{*}{ Samples $^{\mathrm{a}}$} & \multirow{2}{*}{$\begin{array}{c}\text { Density } \pm \text { Standard } \\
\text { deviation }(\%)\end{array}$} & \multicolumn{3}{|c|}{ Average grain size \pm Standard deviation $(\mu \mathrm{m})$} \\
\hline & & Near-surface & Interior & Center \\
\hline Microwave $-2 \mathrm{~g} / 30$ minutes & $99.2 \pm 0.1$ & $0.18 \pm 0.06$ & $0.17 \pm 0.05$ & - \\
\hline Microwave $-14 \mathrm{~g} / 40$ minutes & $99.1 \pm 0.1$ & $0.17 \pm 0.05$ & $0.17 \pm 0.05$ & $0.17 \pm 0.04$ \\
\hline Conventional $-1450^{\circ} \mathrm{C} / 2$ hours & $97.1 \pm 0.2$ & $1.56 \pm 0.91$ & & \\
\hline Conventional $-1500^{\circ} \mathrm{C} / 2$ hours & $98.2 \pm 0.2$ & $3.02 \pm 2.03$ & & \\
\hline Conventional $-1500^{\circ} \mathrm{C} / 6$ hours & $99.1 \pm 0.3$ & $3.87 \pm 2.72$ & & \\
\hline
\end{tabular}

${ }^{a}$ Average particle size of powder measured by centrifugal sedimentation technique was $0.21 \pm 0.08 \mu \mathrm{m}$.
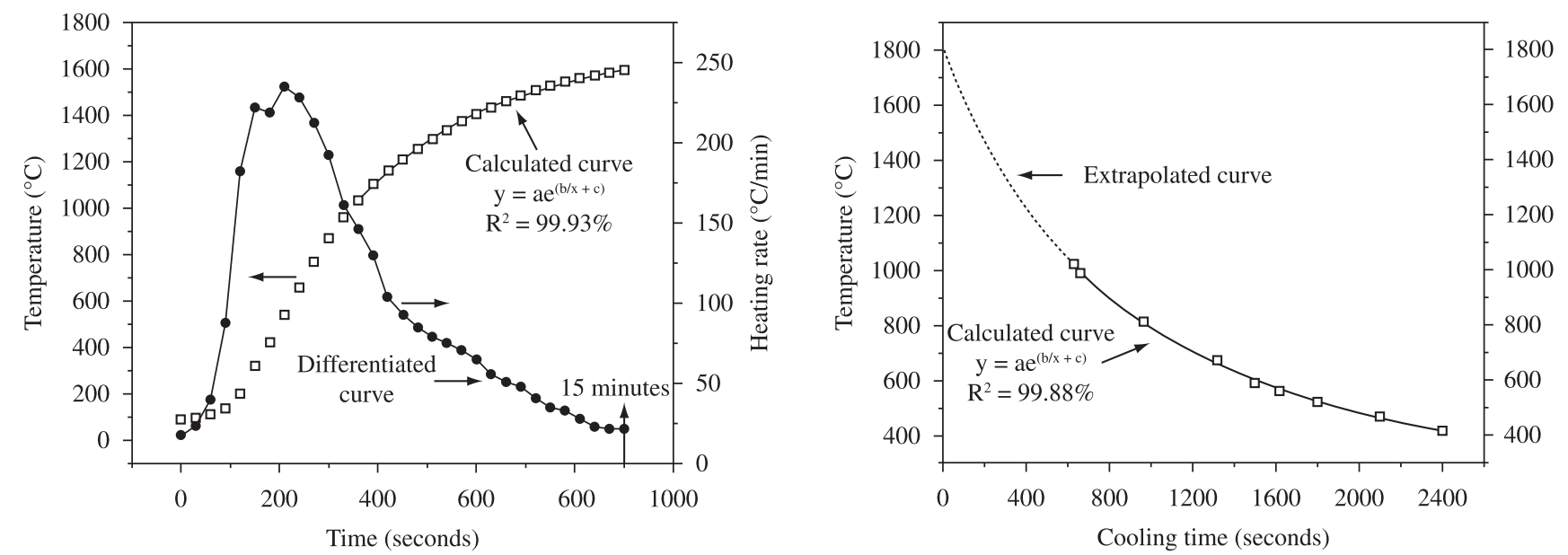

Figure 5. a) Temperature of the sintering arrangement and model fitted, which was calculated using the equation $\mathrm{T}=\mathrm{a} \exp (\mathrm{b} /(\mathrm{c}+\mathrm{t}))$, where $\mathrm{a}=2020.87$, $\mathrm{b}=-191.17$ and $\mathrm{c}=-75.47$ and $\mathrm{b})$ Temperature of the sintering arrangement during cooling and model fitted, which was calculated using the equation $\mathrm{T}=\mathrm{a} \exp (\mathrm{b} /(\mathrm{c}+\mathrm{t}))$, where $\mathrm{a}=64.83, \mathrm{~b}=10035.12$ and $\mathrm{c}=3016.69$.

difference between the temperatures of two treatments that lead to similar microstructures. It is now generally, though by no means unanimously, accepted that a microwave effect exists ${ }^{47}$.

Recent work $^{47}$ investigated the microwave effect in the sintering of different ceramics (zinc oxide, alumina, and zirconia) with quite different abilities to absorb microwave radiation using a hybrid heating system. Compared to conventional heating, the increase in both the onset of densification and the final density achieved was observed to be the greatest in materials that absorbed microwaves most readily. The very lowest dielectric loss powders $\left(\mathrm{Al}_{2} \mathrm{O}_{3}\right)$ showed an extremely small, almost negligible difference in densification with the use of microwave energy compared to conventional heating ${ }^{41,47}$.

Based on our results, we found no evidence of a microwave effect in this study, although we believe in the existence of the microwave effect and had already found evidence of it in previous works $^{39,50}$. Despite the presence or not of a microwave effect, the results obtained here indicate that microwave hybrid heating is a great potential method for sintering submicrometer alumina with uniform microstructures and suppressing grain growth.

\section{Conclusions}

It was concluded from this work that the microwave hybrid fast sintering can be successfully employed in the uniform sintering of almost fully dense submicrometer alumina compacts. The hybrid procedure applied offers an efficient route to produce compacts with densities of $99 \%$ and powder particle size/average grain size ratios higher than 1:2 in sintering cycles of less than 40 minutes.

\section{Acknowledgements}

The authors would like to thank the Brazilian research funding agencies: FAPESQ/MCT/CNPq (State of Paraíba Research Foundation, processes nos. 003/03 and 004/06), CNPq (National Council for Science and Technology, process no. 476382/04-1 and 471415/04-9), and FAPESP (State of São Paulo Research Foundation, process no. $05 / 60095-9,06 / 50121-5$ ) for their financial support of this work.

\section{References}

1. Krell A and Blank P. The Influence of shaping method on the grain size dependence of strength in dense submicrometer alumina. Journal of the European Ceramic Society. 1996; 16:1189-1200.

2. Krell A, Blank P, Ma H, Hutzler T and Nebelung M. Processing of high-density submicrometer $\mathrm{A}_{2} \mathrm{O}_{3}$ for new applications. Journal of the American Ceramic Society. 2003; 86:546-553.

3. Barringer EA and Bowen HK. Formation, packing, and sintering of monodispersed $\mathrm{TiO}_{2}$ powders. Journal of the American Ceramic Society. 1982; 65:C199-C201.

4. German RM. Liquid Phase Sintering. New York: Plenum Press; 1985.

5. Rahaman MN. Ceramic Processing and Sintering. New York: Marcel Dekker; 1995.

6. Stern $\mathrm{LC}$ and Harmer MP. Particle-inhibited grain growth in $\mathrm{Al}_{2} \mathrm{O}_{3}-\mathrm{SiC}$ : I, experimental results. Journal of the American Ceramic Society. 1996; 79:3013-3019.

7. Lin FJT, De Jonghe LC and Rahaman MN. Microstructure refinement of sintered alumina by a two-step sintering technique. Journal of the American Ceramic Society. 1997; 80:2269-2277. 
8. Vernon DM, Rankin J, Caragianis-Broadbridge C and Laube BL. A novel processing route to control grain growth in submicrometer alumina compacts. Journal of the American Ceramic Society. 1999; 82:2969-2977.

9. Shen Z, Johnsson M, Zhao Z and Nygren M. Spark plasma sintering of alumina. Journal of the American Ceramic Society. 2002; 85:1921-1927.

10. Godlinski D, Kuntz M and Grathwohl G. Transparente alumina with submicrometer grains by float packing and sintering. Journal of the American Ceramic Society. 2002; 85:2449-2456.

11. Krell A, Blank P, Ma H, Hutzler T, van Bruggen MPB and Apetz R. Transparent sintered corundum with high hardness and strength. Journal of the American Ceramic Society. 2003; 86:12-18.

12. Zhan GD, Kuntz J, Wan J, Garay J and Mukherjee AK. A Novel processing route to develop a dense nanocrystalline alumina matrix $(<100 \mathrm{~nm})$ nanocomposite material. Journal of the American Ceramic Society. 2002; 86:200-202.

13. Kim HT and Han YH. Sintering of nanocrystalline $\mathrm{BaTiO}_{3}$. Ceramics International. 2004; 30:1719-1723.

14. Duncan JH and Budgen WG. Two-peak firing of beta-alumina. Proceedings of the British Ceramic Society. 1981; 31:221-32.

15. Chen W and Wang XH. Sintering dense nanocrystalline ceramics without final-stage grain growth. Nature. 2000; 404:168-171.

16. Polotai A, Breece K, Dickey E, Randall C and Ragulya A. A novel approach to sintering nanocrystalline barium titanate ceramics. Journal of the American Ceramic Society. 2005; 88:3008-3012.

17. $\mathrm{Li} \mathrm{J}$ and $\mathrm{Ye} \mathrm{Y}$. Densification and grain growth of $\mathrm{Al}_{2} \mathrm{O}_{3}$ nanoceramics during pressureless sintering. Journal of the American Ceramic Society. 2006; 89:139-143.

18. Chu MY, De Jonghe LC, Lin MKF and Lin FJT. Precoarsening to improve microstructure and sintering of powder compacts. Journal of the American Ceramic Society. 1991; 74:2902-2911.

19. Lin FJT, De Jonghe LC and Rahaman MN. Initial coarsening and microstructural evolution of fast-fired and $\mathrm{MgO}$-doped $\mathrm{Al}_{2} \mathrm{O}_{3}$. Journal of the American Ceramic Society. 1997; 80:2891-2896.

20. Harmer MP, Roberts EW and Brook RJ. Rapid sintering of pure and doped $\alpha-\mathrm{Al}_{2} \mathrm{O}_{3}$. Transaction Journal of the British Ceramic Society. $1979 ; 78: 22-25$.

21. Harmer MP and Brook RJ. Fast firing - Microstructural benefits. Transaction of the British Ceramic Society. 1981; 80:147-148.

22. Baumgarter CE. Fast firing and conventional sintering of lead zirconate titanate ceramics. Journal of the American Ceramic Society. 1988; 71:C350-C353.

23. Tian YL, Johnson DL and Brodwin ME. Ultrafine microstructure of $\mathrm{Al}_{2} \mathrm{O}_{3}$ produced by microwave sintering. In: Messing GL, Fuller ER and Hausner H, editors. Ceramic Transactions, Vol. 1. Ceramic Powder Science IIB. Westerville: American Ceramic Society; 1988. p. 925-932.

24. Garcia DE, Seidel J, Janssen R, Claussen N. Fast firing of alumina. Journal of the American Ceramic Society. 1993; 15: 935-938.

25. Link G, Feher L, Thumm M, Ritzhaupt-Kleissl MJ, Böhme R and Weisenburger A. Sintering of advanced ceramics using a 30-GHz, 10-kW, CW industrial gyrotron. IEEE Transaction on Plasma Science. 1999; 27:547-554.

26. Fliflet AW, Bruce RW, Fischer RP, Lewis D, Kurihara LK, Bender BA et al. A study of millimeter-wave sintering of fine-grained alumina compacts. IEEE Transaction on Plasma Science. 2000; 28:924-935.

27. Clark DE and Sutton WH. Microwave processing of materials. Annual Reviews of Materials Science. 1996; 26:299-331.

28. Birnboim A, Gershon D, Calame J, Birman A, Carmel Y, Rodgers J et al. Comparative study of microwave sintering of zinc oxide at 2.45, 30 and 83GHz. Journal of the American Ceramic Society. 1998; 81:1493-1501.

29. Menezes RR, Souto PM, Fagury-Neto E and Kiminami, RHGA. Sintering of ceramics. In: Shulz RL and Folz DC, editors. Proceedings of the Fourth World Congress on Microwave and Radio Frequency Application; 2004. Arnold: The Microwave Working Group; 2004. p. 118-132.

30. Sutton W. Microwave processing of ceramic materials. American Ceramic Society Bulletin. 1989; 68:376-386.
31. Brosnan KH, Messing GL and Agrawal DK. Microwave sintering of alumina at $2.45 \mathrm{GHz}$. Journal of the American Ceramic Society. 2003; 86:1307-1312.

32. Kim SW and Khalil KAR. High-frequency induction heat sintering of mechanically alloyed alumina-yttria-stabilized zirconia nano-bioceramics. Journal of the American Ceramic Society. 2006; 89:1280-1285.

33. Ewsukw KG, Ellerbyz DT and DiAntonio CB. Analysis of nanocrystalline and microcrystalline $\mathrm{ZnO}$ sintering using master sintering curves. Journal of the American Ceramic Society. 2006; 89:2003-2009.

34. Liu J, Shen Z, Nygren M, Su B and Button TW. Spark plasma sintering behavior of nano-sized $(\mathrm{Ba}, \mathrm{Sr}) \mathrm{TiO}_{3}$ powders: Determination of sintering parameters yielding nanostructured ceramics. Journal of the American Ceramic Society. 2006; 89:2689-2694.

35. Anselmi-Tamburini U, Garay JE and Munir ZA. Fast low-temperature consolidation of bulk nanometric ceramic materials. Scripta Materialia. 2006; 54:823-828.

36. Chinelatto ASA, Pallone E, Trombine V and Tomasi R. Influence of the heating curve control on sintering of the ultra fine alumina powders obtained by high-energy milling. In: Proceedings of 4th International Latin American Conference on Powder Technology; 2003; Guarujá, Brazil; 2003. p. 451-459.

37. Chinelatto ASA. Sinterização de pós de alumina ultra-fina para obter altas densidades e pequeno tamanho de grão [Ph.D Thesis]. São Carlos, Federal University of São Carlos; 2002.

38. Kiminami RHGA, Menezes RR and Souto PM. World Intellectual Property Organization Patent, WO 2008/077224 A2. 3 July 2008.

39. Souto PM, Menezes RR and Kiminami RHGA. Microwave hybrid sintering of mullite powders. American Ceramic Society Bulletin. 2007; 86:9201-9207.

40. ASTM International. ASTM C-378-88. Standard test method for water absorption, bulk density, apparent porosity and apparent specific gravity of fired whiteware products. EUA: ASTM; 2006.

41. Menezes RR and Kiminami RHGA. Microwave sintering of aluminazirconia, nanocomposites. Journal of Materials Processing Technology. 2008; 203:513-519.

42. Grellinger DJ and Janney MA. Temperature measurement in a $2.45 \mathrm{GHz}$ microwave furnace. In: Snyder WB, Sutton WH, Johnson DL and Iskander MF, editors. Microwave Processing of Materials II, Pittisburgh: Materials Research Society; 1989. p. 529-538.

43. Birnboim A and Carmel Y. Simulation of microwave sintering of ceramic bodies with complex geometry. Journal of the American Ceramic Society. 1999; 82:302-330.

44. Pert E, Carmel Y, Birnboim A, Olorunyolemi T, Gershon D, Calame $\mathrm{J}$ et al. Temperature measurements during microwave processing: the significance of thermocouple effects. Journal of the American Ceramic Society. 2001; 84:1981-1986.

45. Fujitsu S, Ikegami M and Hayashi T. Sintering of partially stabilized zirconia by microwave heating using $\mathrm{ZnO}-\mathrm{MnO}_{2}-\mathrm{Al}_{2} \mathrm{O}_{3}$ plates in a domestic microwave oven. Journal of the American Ceramic Society. 2000; 83:2085-2088.

46. Manfredini T and Pennisi L. Recent innovations in fast firing process. In: Henkes VE, Onoda GY and Carty WM, editors. Science of Whitewares. Westville: American Ceramic Society; 1996. p. 213-224.

47. Wang J, Binner J, Vaidhyanathan B, Joomun N, Kilner J, Dimitrakis G et al. Evidence for the microwave effect during hybrid sintering. Journal of the American Ceramic Society. 2006; 89: 1977-1982.

48. Vaidhyanathan B, Singh AP, Agrawal DK, Shrout TR, Roy R and Ganguly $S$. Microwave effects in lead zirconium titanate synthesis: enhanced kinetics and changed mechanisms. Journal of the American Ceramic Society. 2001; 84:1197-1201.

49. Roy R, Peelamedu R, Hurtt L, Cheng J and Agrawal D. Definitive experimental evidence for microwave effects: radically new effects of separated $\mathrm{E}$ and $\mathrm{H}$ fields, such as decrystallization of oxides in seconds. Materials Research Innovations. 2002; 6:128-132.

50. Menezes RR, Souto PM and Kiminami RHGA. Microwave hybrid fast sintering of porcelain bodies. Journal of Materials Processing Technology. 2007; 190:223-227. 